\title{
ANALISA JENIS, BENTUK DAN KELIMPAHAN MIKROPLASTIK DI SUNGAI SEI SIKAMBING MEDAN
}

\author{
Novrida Harpah ${ }^{1)}$, Isra Suryati ${ }^{2)}$ Ronald Leonardo ${ }^{3)}$, Anita Risky ${ }^{4)}$ Putri Ageng ${ }^{5)}$, Robiatul \\ Addauwiyah") \\ ${ }^{123456}$ Program Studi Teknik Lingkungan, Universitas Sumatera Utara \\ email: novridahasibuan@usu.ac.id
}

\begin{abstract}
Abstrak
Abstrak: Sungai adalah salah satu jalur masuknya plastik ke lautan. Plastik bersifat presisten dan tahan lama tetapi paparan radiasi ultraviolet serta abrasi fisik mampu memecah plastik menjadi puing-puing kecil berukuran mikro sampai dengan nano yang disebut mikroplastik. Penelitian ini bertujuan untuk menganalisa jenis, bentuk dan jumlah mikroplastik di air dan sedimen Sungai Sei Sikambing Medan. Metode penelitian dilakukan dengan pengambilan sampel air dan sedimen sungai berdasarkan SNI 03-7016-2004 dan sampel merupakan hasil dari gabungan tempat (integrated samples). Pemisahan mikroplastik dilakukan dengan penyaringan, pengancuran senyawa organik, pemisahan berdasarkan berat jenis dan penyaringan menggunakan vacuum. Identifikasi jenis dan bentuk mikroplastik dilakukan dengan menggunakan FTIR dan menganalisa kelimpahan mikroplastik dilakukan dengan menggunakan mikroskop. Hasil penelitian menunjukkan Sungai Sei Sikambing mengandung mikroplastik jenis polietilen, polipropilen dan polisterin dengan bentuk film, fragment, granule, foam dan fiber. Jumlah rata-rata mikroplastik di air Sungai Sei Sikambing adalah 28,6 partikel/250 ml air sungai dan 32,3 partikel/100 g berat kering sedimen Sungai Sei Sikambing.
\end{abstract}

Kata kunci: Mikroplastik, Sei Sikambing, Plastik, Medan

Abstract: Rivers are one of the plastics pathways to enter the oceans. Plastics are persistent and durable, but ultraviolet radiation and physical abrasion that can break down plastics into small, micro to nano sized and called microplastic. This study aims to analyze the type, shape and amount of microplastics on the water and sediment in Sei Sikambing River Medan. The method of investigation conducted with sampling water and sediment based on SNI 03-7016-2004 and the method used is integrated sample. The step of microplastic separation are filtration, digestion, separation by density and identification and filtration by vacuum. To identify type and shapes of microplastics used FTIR and abundance of microplastics used microscopy. The results showed that the Sei Sikambing River contained microplastic with the types of microplastics are polyethylene, polypropylene and polystyrene, the shapes are film, fragment, granule, foam and fiber. The average amount of microplastics in Sei Sikambing River water is 28.6 particles $1250 \mathrm{ml}$ river water and 32.3 particles $100 \mathrm{~g}$ dry weight of Sei Sikambing River sediment.

Keywords: Microplastics, Sei Sikambing River, polyethylene, polypropylene, polystyrene

\section{PENDAHULUAN}

Indonesia merupakan kontributor polutan plastik ke laut terbesar di dunia setelah China dengan besaran $0,48-1,29$ juta metrik ton plastik/tahun (Widianarko and Hantoro, 2018). Sungai merupakan jalur utama masuknya plastik ke lautan. (Kataoka et al., 2019)

Sungai Deli merupakan DAS terbesar di Sumatera Utara dengan tujuh sub DAS dan salah satunya sub DAS Sei Sikambing yang memiliki peran penting terhadap kebutuhan air di Kota Medan (Zevri, 2019). Air Sungai Deli ini akan bermuara ke laut belawan yang merupakan salah satu sumber pangan laut masyarakat Kota Medan.

Sub DAS Sei Sikambing memiliki panjang sungai utama $18,73 \mathrm{Km}$. Das Sei Sikambing melintasi 3 kecamatan yaitu Kecamatan Medan Selayang, Medan Baru dan Medan Petisah (Zevri, 2019). Kondisi 
eksisting menunjukkan kondisi bantaran Sungai Sei Sikambing didominasi pemukiman kumuh dengan kondisi air yang berwarna gelap, beraroma dan banyak terdapat sampah baik sampah organik maupun sampah anorganik.

Plastik mengandung monomer beracun dan zat adiktif seperti bisphenol A dan phthalates dapat larut kedalam air laut dan mempengaruhi organisme air yang ada (Mohamed Nor and Obbard, 2014). Plastik umumnya bersifat persiten dan tahan lama tetapi degradasi oksidatif yang disebabkan oleh paparan radiasi ultraviolet dalam waktu lama dan abrasi fisik mampu memecah puing-puing plastik menjadi partikel yang lebih kecil berukuran micrometer sampai dengan nanometer (Widianarko and Hantoro, 2018).

Polimer plastik yang memiliki ukuran kurang dari $5 \mathrm{~mm}$ disebut mikroplastik (Alam et al., 2019). Mikroplastik berdasarkan proses pembentukannya dapat dibagi menjadi dua jenis, yaitu primer dan sekunde. Mikroplastik primer adalah plastik yang memang memiliki ukuran mikro dan biasanya ditemukan dalam pembersih dan produk kosmetik. Mikroplastik sekunder adalah yang terbentuk dari plastik yang sudah ada di lingkungan dan terfragmentasi menjadi plastik yang lebih kecil menjadi mikroplastik (Ramadan and Sembiring, 2020).

Mikroplastik tidak hanya ada di air permukaan, tetapi juga di sedimen, tanah, dan organisme. Mikroplastik dengan ukuran khusus dan sifat stabil adalah tempat berkembang biak bagi mikroorganisme dan pembawa polutan (Pan et al., 2019). Organisme akuatik dapat dengan mudah menelan mikroplastik karena ukurannya yang kecil dan menyerupai larva organisme termasuk plankton (Kataoka et al., 2019).

Kelimpahan dan distribusi mikroplastik ditentukan oleh faktor lingkungan dan faktor antropogenik. Faktor lingkungan termasuk arus gelombang, pasang surut, siklon, arah angin dan hidrodinamika sungai(Shahul Hamid et al., 2018). Faktor antropogenik meliputi kepadatan penduduk (Kataoka et al., 2019)

Untuk itu, penelitian ini bertujuan untuk menganalisa jenis, bentuk dan kelimpahan mikroplastik di Sungai Sei Sikambing yang sepanjang alirannya terdapat banyak pemukiman warga dan aliran sungai ini menuju ke Sungai Deli dan berakhir di laut Belawan yang merupakan salah satu sumber pangan laut masyarakat Kota Medan. Hasil penelitian ini diharapkan memberikan gambaran awal pencemaran mikroplastik di sungai yang melintasi Kota Medan dan mampu mendorong manajemen terintegrasi dalam pengelolaan sampah di Kota Medan.

\section{METODE PENELITIAN}

\section{Penentuan lokasi sampling}

Penentuan lokasi sampling di Sungai Sei Sikambing dilakukan dengan merujuk kepada SNI 06-2412199 yaitu Metode pengambilan contoh kualitas air dan mempertimbangkan kondisi eksisting di lapangan termasuk kemudahan dalam pengambilan sampel air dan sedimen. Lokasi pengambilan sampel dilakukan di tiga lokasi, lokasi pertama setelah pertemuan kedua anak sungai, lokasi kedua di kawasan padat penduduk dan lokasi ketiga sebelum pertemuan dengan Sungai Deli.

Adapun lokasi pengambilan sampel sebagai berikut:

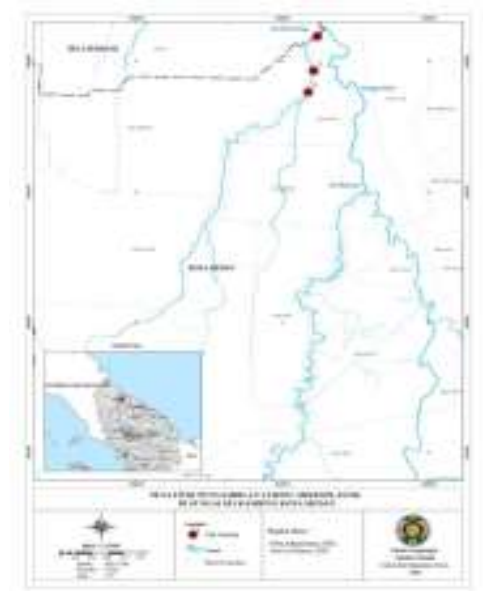

Gambar 1. Lokasi Pengambilan Sampel 


\section{Pengambilan Sampel Air}

Pengambilan sampel air dan sedimen dilakukan pada tanggal 16 juli 2020 dengan kondisi cuaca cerah. Pengukuran hidrodinamika sungai meliputi pengukuran lebar sungai, kedalaman sungai dan kecepatan alir Sungai Sei Sikambing dengan metode bola apung sesuai dengan SNI 8066:2015 yaitu tata cara pengukuran debit aliran sungai dan saluran terbuka menggunakan alat ukur arus dan pelampung dilakukan sebelum pengambilan sampel air dan sedimen. Hal ini dilakukan untuk menentukan waktu pengambilan sampel di lokasi selanjutnya dan titik pengambilan sampel.

Pengambilan sampel air dan sedimen dilakukan berdasarkan SNI 037016-2004 tentang tata cara pengambilan contoh dalam rangka pemantauan kualitas air pada suatu daerah pengaliran sungai. Metode yang digunakan adalah gabungan tempat (integrated samples). Pengambilan sampel dilakukan pada pinggiran kiri, tengah dan pinggiran kanan sungai (Ebere et al., 2019). Pengambilan sampel air dilakukan pada kedalaman setengah kedalaman total sungai $(1 / 2 \mathrm{~h})$ dan kedalaman sedimen $0-10 \mathrm{~cm}$ dari permukaan atas sedimen. Kelimpahan mikroplastik pada kedalam 0-10 cm cenderung tinggi (Dewi, Intan Sari, 2015). Sampel air yang telah didapat kemudian diawetkan pada cool box dengan suhu $4^{0} \mathrm{C}$ (Alam et al., 2019).

\section{Analisa Laboratorium}

Sampel air dan sedimen yang akan dianalisa jenis, bentuk dan jumlahnya harus dilakukan pemisahaan dengan zat-zat terlarut yang terkandung di dalam sampel air dan sedimen seperti senyawa organik. Proses pemisahan mikroplastik dengan air dan sedimen terdiri dari 3 tahap utama yaitu tahap penghancuran senyawa organik, pemisahaan berdasarkan berat jenis dan penyaringan dengan vakum.

Sampel air sungai sebanyak $1 \mathrm{~L}$ di saring dan ditambahkan $\mathrm{NaCl} 30 \%$ sebanyak 400ml, diaduk dan didiamkan selama satu malam, setelah itu ditambahkan $10 \quad \mathrm{ml} \mathrm{H}_{2} \mathrm{O}_{2} \quad 30 \%$ dan diaduk selama 5 menit dan biarkan selama 2 malam. Larutan sampel disaring dengan metode vacuum dan keringkan kertas saring dalam desikator selama 1 malam dan analisa bentuk dan jumlah dengan menggunakan mikroskop. Mikroplastik di dalam kertas saring diuji dimasukkan ke dalam botol vial dan dilakukan pengujian jenis polimer dengan FTIR.

Sampel sedimen basah sebanyak 1 $\mathrm{kg}$ dikeringkan dalam oven dengan suhu $75^{\circ} \mathrm{C}$ selama \pm 24 jam (sampai kering). Ambil $100 \mathrm{~g}$ berat kering sedimen dan tambahkan dengan $400 \mathrm{ml}$ $\mathrm{NaCl} 30 \%$ diaduk selama 2 menit dan diamkan selama 1 malam. Larutan $\mathrm{H}_{2} \mathrm{O}_{2}$ sebanyak $10 \mathrm{ml}$ ditambahakn dan diaduk selama 5 menit dan didiamkan selama 2 malam. Larutan tsb kemudian disaring dengan metode vakum dan keringkan kertas saring dalam desikator selama 1 malam, analisa bentuk dan jumlah mikroplastik dengan mikroskop dan analisa jenis mikroplastik yang terkandung di dalam sampel dengan FTIR.

\section{Analisa Data}

Analisa data bentuk mikroplastik yang didapat akan disesuaikan dengan bentuk mikroplastik seperti line, foam, fragmen, film, pellet dan lainnya dari penelitian terdahulu. Jenis mikroplastik yang dianalisa hanya polietilen, polistiren dan polipropilen, Data panjang gelombang dari hasil uji FTIR akan disesuaikan dengan panjang gelombang spektrum standar untuk database polimer polietilen, polistiren dan polipropilen. Data kelimpahan mikroplastik didapatkan dalam satuan jumlah partikel/250 ml air untuk 
mikroplastik di dalam air sungai dan jumlah partikel/ $100 \mathrm{~g}$ berat kering sedimen untuk mikroplastik di dalam sedimen sungai.

\section{HASIL DAN PEMBAHASAN}

\section{Hidrogeometri Sungai Sei Sikambing}

Sungai Sei Sikambing memiliki lebar sungai rata-rata $16,7 \mathrm{~m}$ dengan kedalaman sungai rata-rata $0,7 \mathrm{~m}$ dan kecepatan air rata-rata $0,44 \mathrm{~m} / \mathrm{s}$.

\section{Bentuk Mikroplastik}

Bentuk mikroplastik di Sungai Sei Sikambing di dominasi oleh fragment yang ditemukan di semua lokasi sampling baik air dan sedimen sungai. Bentuk fragment memiliki karakteristik fisik yaitu bentuk yang tidak beraturan, tebal dengan tepi yang tajam. (Ebere $e t$ $a l .$, 2019). Adapun bentuk mikroplastik di lokasi samping adalah sebagai berikut:

Tabel 1. Bentuk Mikroplastik

\begin{tabular}{|c|c|c|}
\hline Lokasi & Air & Sedimen \\
\hline Sei Sikambing1 & Film, Fragment & Fragment \\
\hline Sei Sikambing2 & $\begin{array}{c}\text { Film, Granule, } \\
\text { Foam,Fragment }\end{array}$ & $\begin{array}{c}\text { Granule, } \\
\text { Fragment }\end{array}$ \\
\hline Sei Sikambing3 & Fiber, Film, & $\begin{array}{c}\text { Film, } \\
\text { Fragment, } \\
\end{array}$ \\
\hline
\end{tabular}

Bentuk-bentuk mikroplastik di sedimen sungai Sei Sikambing adalah sebagai berikut:

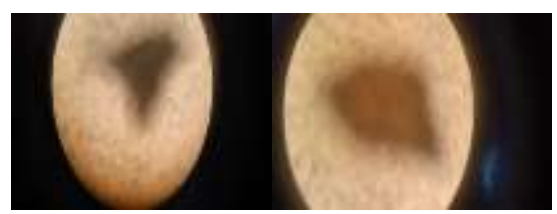

a. Fragment

b. Film

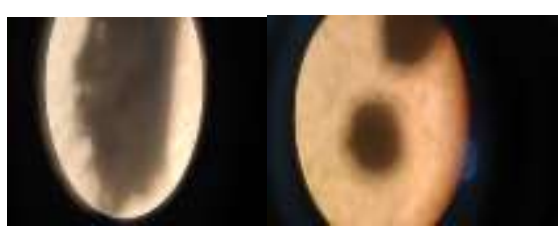

c. Foam

d. Granule

Gambar 2. Partikel fragment (a), film(b),form (c), granule(d) pada sedimen sungai
Bentuk-bentuk mikroplastik di air sungai Sei Sikambing adalah sebagai berikut:
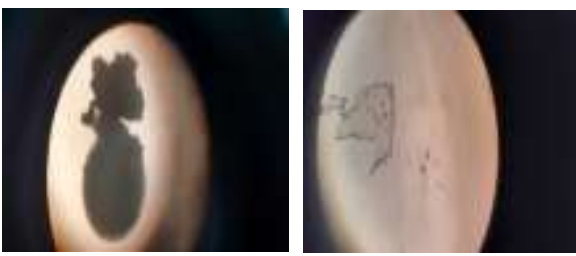

a.Granule dan foam b. Film

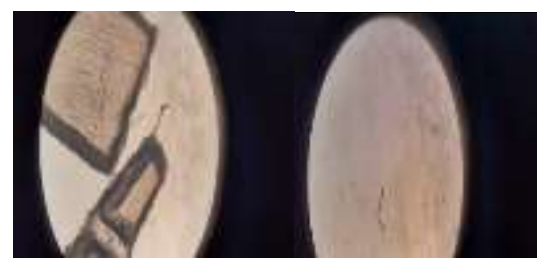

c.Fragment d. Fiber

Gambar 3. Granule dan foam (a), film(b),fragment(c), fiber(d) pada air sungai

Penelitian menunjukkan bahwa asal dan jalur masuknya mikroplastik menentukan bentuk dari mikroplastik tersebut (Pan et al., 2019). Pencemaran mikroplastik dari sumber antropogenik seperti limbah rumah tangga menyumbang mikroplastik berbentuk fragment terbesar. (Ayuningtyas, 2019). DAS Sei Sikambing didominasi oleh wilayah pemukiman sehingga bentuk fragmen ditemukan di semua lokasi sampling.

Mikroplastik yang berbentuk tidak beraturan memiliki mekanisme pengendapan yang kompleks dibandingkan dengan mikroplastik berbentuk bulat (Horton and Dixon, 2018).

Mikroplastik yang berbentuk film ditemukan di semua lokasi sampling untuk air sungai. Bentuk film memiliki karakteristik fisik fleksibel dan tipis (Ebere et al., 2019). Mikroplastik bentuk film diduga berasal dari potongan kantongan plastik sekali pakai yang terdegradasi. Mikroplastik yang mengapung dengan bentuk yang tidak beraturan cenderung tertarik ke dalam 
badan air dan tertahan di badan air (Horton and Dixon, 2018). Oleh karena itu, partikel dengan bentuk film dan fragmen cenderung banyak ditemukan di air sungai.

Bentuk mikroplastik yang ditemukan di Sungai Sei Sikambing didominasi oleh bentuk mikroplastik sekunder yang terbentuk karena degradasi sinar ultraviolet dan abrasi fisik yang menyebabkan plastik ukuran mikro menjadi plastik berukuran mikro bahkan nano. Mikroplastik sekunder seperti film dan fragmen berasal dari pelapukan kemasan plastik atau kantong plastik (Fahrenfeld et al., 2019)

\section{Jenis Mikroplastik}

Hasil uji FTIR untuk sampel mikroplastik dari air dan sedimen sungai akan disesuaikan dengan tabel IR septrum untuk melihat jenis polimer yang sesuai yaitu polietilen, polipropilen atau polistiren.

Hasil peak dari pengujian FTIR untuk sampel sedimen Sungai Sei Sikambing dari ketiga lokasi mengandung ikatan-ikatan dengan panjang gelombang sebagai berikut: $2914,10 \mathrm{~cm}^{-1}, 2846,74 \mathrm{~cm}^{-1}, 1463,5 \mathrm{~cm}^{-}$ $1,1373,99 \mathrm{~cm}^{-1}, 720 \mathrm{~cm}^{-1}, 539,84 \mathrm{~cm}^{-1}$. Panjang gelombang 2914,10 $\mathrm{cm}^{-1}$, $2846,74 \mathrm{~cm}^{-1}, 1463,5 \mathrm{~cm}^{-1}$ mendekati dengan panjang gelombang standard untuk Polipropilen. Penelitian yang dilakukan di ekosistem mangrove singapura menemukan karakteristik panjang gelombang $2917 \mathrm{~cm}^{-1}, 2849$ $\mathrm{cm}^{-1}$ and $1468 \mathrm{~cm}^{-1}$ dan mendekati panjang gelombang Polietilen (Mohamed Nor and Obbard, 2014). Panjang gelombang mikroplastik yang diuji juga menghasilkan panjang gelombang sebagai berikut $2914,10 \mathrm{~cm}^{-}$ 1, 2846,74 $\mathrm{cm}^{-1}, 1463,5 \mathrm{~cm}^{-1}, 1373,99$ $\mathrm{cm}^{-1}$. Panjang gelombang ini mendekati panjang gelombang standard untuk polipropilen. Serat transparan dari Sungei Buloh diidentifikasi sebagai polipropilen dengan spektrum FTIR standar memiliki puncak mendekati bilangan gelombang, 2860-2960 cm-1 , $1452 \mathrm{~cm}-1$ dan $1375 \mathrm{~cm}-1$ (Mohamed Nor and Obbard, 2014).

Panjang gelombang $720 \mathrm{~cm}^{-1}$ mendekati panjang gelombang cincin benzene yang merupakan salah satu gugus yang dimiliki oleh Polistiren. Panjang gelombang 756 dan 698,2 menunjukkan subsituen pada cincin benzene. (Fang, Xuan and Li, 2010)

Untuk itu, sedimen sungai Sei Sikambingmengandung mikroplastik jenis polietilen, polipropilen dan polistiren.

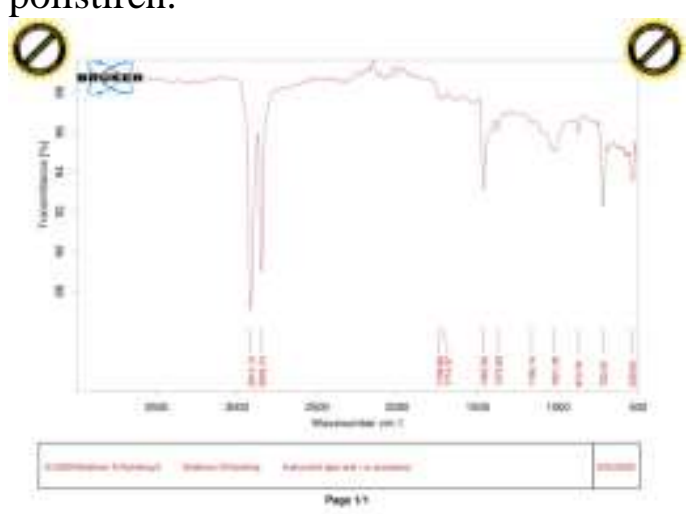

Gambar 4. Hasil Uji FTIR untuk Sedimen Sei Kambing

Hasil peak dari pengujian FTIR untuk sampel air Sungai Sei Sikambing dari ketiga lokasi mengandung ikatanikatan dengan panjang gelombang sebagi berikut: $2913.47 \mathrm{~cm}^{-1}, 2846.07$ $\mathrm{cm}^{-1}, \quad 1463.13 \mathrm{~cm}^{-1}, 1371.86 \mathrm{~cm}^{-1}$, $1028.23 \mathrm{~cm}^{-1}, 721.33 \mathrm{~cm}^{-1}$ dan 563.03 $\mathrm{cm}^{-1}$. Panjang gelombang tersebut mendekati panjang gelombang standard untuk polietilen, polipropilen dan polistiren. Oleh karena itu, air Sungai Sei Sikambing mengandung mikroplastik jenis polietilen, polipropilen dan polistiren. Hasil uji FTIR untuk air sungai Sei Sikambing menghasilkan beberapa noise yang mengindikasikan ada beberapa senyawa organik yang terkandung di dalam air sungai belum larut seluruhnya larut dengan penambahan $\mathrm{H}_{2} \mathrm{O}_{2} \quad 10 \%$ sebanyak $10 \mathrm{ml}$ sehingga pada 
penelitian selanjutnya volume $\mathrm{H}_{2} \mathrm{O}_{2}$ $10 \%$ baiknya ditambah guna mengurangi kehadiran noise.

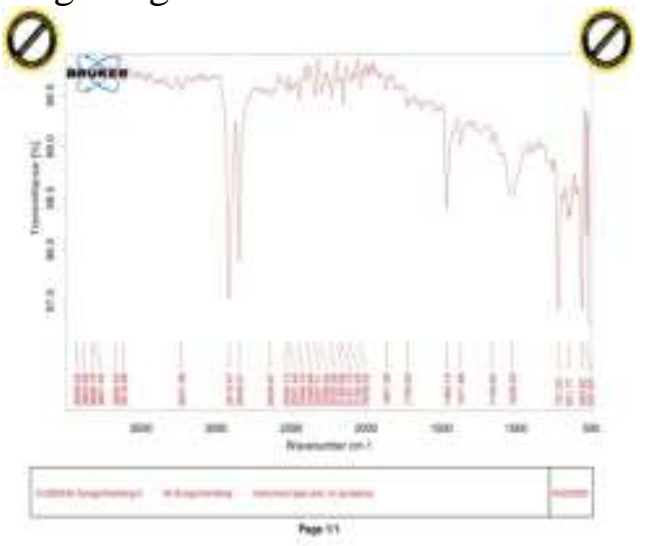

Gambar 5. Hasil Uji FTIR Air Sungai Sei Kambing

Polietilen dan Polipropilen hampir ditemukan di semua bagian dari Benua Asia. (Shahul Hamid et al., 2018). Polietilen dan Polipropilen banyak ditemukan di air tawar karena memiliki densitasnya $0.83-0.85 \mathrm{~g} \mathrm{~mL}^{-1}$ dan lebih rendah dari air. (Ramadan and Sembiring, 2020).

\section{Kelimpahan mikroplastik}

Data kelimpahan mikroplastik di Sungai Sei Sikambing adalah sebagai berikut:

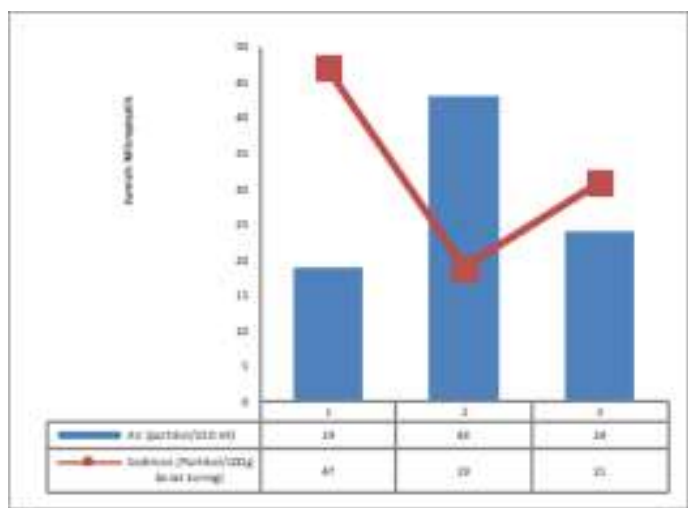

Gambar 5. Jumlah Mikroplastik di air dan sedimen Sungai Sei Kambing.

Jumlah mikroplastik rata-rata di air Sungai Sei Sikambing adalah 28,6 partikel/250 $\mathrm{ml}$ air sungai dan 32,3 partikel/100g berat kering sedimen Sungai Sei Kambing. Jumlah mikroplastik di Sungai Sei Sikambing lebih tinggi dibandingkan dengan jumlah mikroplastik di Sungai Ciwalengke Majalaya, Muara Badak di Kutai Kartenegara, Sungai Tame UK. Jumlah mikroplastik di Sungai Sei Sikambing mendekati jumlah mikroplastik di Sungai Beijing. Adapun perbandingan jumlah mikroplastik di beberapa daerah adalah sebagai berikut:

Tabel 2. Jumlah mikroplastik di beberapa daerah

\begin{tabular}{|c|c|c|}
\hline Lokasi & $\begin{array}{c}\text { Jumlah } \\
\text { Mikroplastik }\end{array}$ & Reference \\
\hline $\begin{array}{l}\text { Sungai } \\
\text { Ciwalengke, } \\
\text { Majalaya }\end{array}$ & $\begin{array}{l}5.85 \pm 3.28 \\
\text { partikel per liter } \\
3.03 \pm 1.59 \text { per } \\
100 \mathrm{~g} \text { berat kering } \\
\text { sedimen }\end{array}$ & $\begin{array}{l}\text { (Alam et } \\
\text { al., 2019) }\end{array}$ \\
\hline $\begin{array}{l}\text { Muara Badak, } \\
\text { Kutai } \\
\text { Kartenegara }\end{array}$ & $\begin{array}{l}69,3-90,12 \\
\text { partikel/kg } \\
\text { sedimen kering }\end{array}$ & $\begin{array}{l}\text { (Dewi, } \\
\text { Intan Sari, } \\
2015)\end{array}$ \\
\hline $\begin{array}{l}\text { Sungai } \\
\text { Beijing }\end{array}$ & $\begin{array}{l}17,8-54,4 \\
\text { partikel per } 100 \mathrm{~g} \\
\text { berat kering }\end{array}$ & $\begin{array}{l}\text { (Tibbetts et } \\
\text { al., 2018) }\end{array}$ \\
\hline $\begin{array}{l}\text { Sungai Sei } \\
\text { Sikambing }\end{array}$ & $\begin{array}{lr}28,6 & \text { partikel/250 } \\
\text { ml air } & \text { sungai } \\
32,3 & \text { partikel } \\
/ 100 \mathrm{~g} & \text { berat } \\
\text { kering sedimen }\end{array}$ & $\begin{array}{l}\text { Novrida et } \\
a l, 2020)\end{array}$ \\
\hline
\end{tabular}

Kondisi eksisting di Sungai Sei Sikambing menunjukkan bahwa terdapat banyak sampah baik sampah organik maupun anorganik. Air Sungai Sei Sikambing berwarna coklat dan berbau. Selain itu, pemukiman kumuh juga berada di sepanjang aliran Sungai Sei Kambing, Kawasan kumuh dengan kondisi sanitasi yang buruk dari warga yang melakukan aktivitas mandi, cuci, kakus di sungai, kemungkinan dapat mempengaruhi kelimpahan partikel mikroplastik seperti kegiatan pencucian dapat menghasilkan serat yang robek dari pakaian, atau penggunaan deterjen. (Alam et al., 2019).

\section{KESIMPULAN}

Sungai Sei Sikambing yang melintasi Kota Medan mengandung mikroplastik dengan jumlah rata-rata adalah 28,6 
partikel/250 $\mathrm{ml}$ air sungai dan 32,3 partikel/100g berat kering sedimen Sungai Sei Sikambing dan bila dibandingkan dengan jumlah mikroplastik dari beberapa sungai di beberapa daerah dan negara maka jumlah ini termasuk tinggi. Jenis mikroplastik yang terkandung di air dan sedimen Sungai Sei Sikambing adalah polipropilen, polietilen dan polistiren dengan bentuk fragmen, film, granule, fiber dan foam. Bentuk mikroplastik erat kaitannya dengan sumber mikroplastik. Mikroplastik yang ditemukan di sungai Sei Sikambing didominasi oleh mikroplastik sekunder yaitu makroplastik yang terdegradasi.

\section{DAFTAR PUSTAKA}

Alam, F. C. et al. (2019) 'Microplastic distribution in surface water and sediment river around slum and industrial area (case study: Ciwalengke River, Majalaya district, Indonesia)', Chemosphere, 224, pp. 637-645. doi: 10.1016/j.chemosphere.2019.02.188.

Ayuningtyas, W. C. (2019) 'Kelimpahan Mikroplastik Pada Perairan Di Banyuurip, Gresik, Jawa Timur', JFMR-Journal of Fisheries and Marine Research, 3(1), pp. 41-45. doi: 10.21776/ub.jfmr.2019.003.01.5.

Dewi, Intan Sari, A. A. B. dan I. R. R. (2015) 'Distribusi mikroplastik pada sedimen di Muara Badak, Kabupaten Kutai Kartanegara Distribution of microplastic at sediment in the Muara Badak Subdistrict, Kutai Kartanegara Regency', Depik, 4(3), pp. 121-131.

Ebere, E. C. et al. (2019) 'Macrodebris and microplastics pollution in Nigeria: First report on abundance, distribution and composition', Environmental Health and Toxicology, 34(4). doi: 10.5620/eaht.e2019012.

Fahrenfeld, N. L. et al. (2019) 'Source tracking microplastics in the freshwater environment', TrAC - Trends in Analytical Chemistry, 112, pp. 248254. doi: 10.1016/j.trac.2018.11.030.

Fang, J., Xuan, Y. and Li, Q. (2010) 'Preparation of polystyrene spheres in different particle sizes and assembly of the PS colloidal crystals', Science China Technological Sciences, 53(11), pp. 3088-3093. doi: 10.1007/s11431010-4110-5.

Horton, A. A. and Dixon, S. J. (2018) 'Microplastics: An introduction to environmental transport processes', Wiley Interdisciplinary Reviews: Water, 5(2), p. e1268. doi: 10.1002/wat2.1268.

Kataoka, T. et al. (2019) 'Assessment of the sources and inflow processes of microplastics in the river environments of Japan', Environmental Pollution, 244, pp. 958-965. doi: 10.1016/j.envpol.2018.10.111.

Mohamed Nor, N. H. and Obbard, J. P. (2014) 'Microplastics in Singapore's coastal mangrove ecosystems', Marine Pollution Bulletin, 79(1-2), pp. 278283.

doi: 10.1016/j.marpolbul.2013.11.025.

Pan, Z. et al. (2019) 'Microplastics in the Northwestern Pacific: Abundance, distribution, and characteristics', Science of the Total Environment, 650, pp. 1913-1922. doi: 10.1016/j.scitotenv.2018.09.244.

Ramadan, A. H. and Sembiring, E. (2020) 'Occurrence of Microplastic in surface water of Jatiluhur Reservoir', E3S Web of Conferences, 148, pp. 1-4. doi: $10.1051 / \mathrm{e} 3$ sconf/202014807004.

Shahul Hamid, F. et al. (2018) 'Worldwide distribution and abundance of microplastic: How dire is the situation?', Waste Management and Research, 36(10), pp. 873-897. doi: 


\section{$10.1177 / 0734242 X 18785730$.}

Tibbetts, J. et al. (2018) 'Abundance, distribution, and drivers of microplastic contamination in urban river environments', Water (Switzerland), 10(11). doi: 10.3390/w10111597.

Widianarko, B. and Hantoro, I. (2018) Mikroplastik Mikroplastik dalam Seafood Seafood dari Pantai Utara Jawa. Available at: www.unika.ac.id.

Zevri, A. (2019) 'Studi Pemetaan Daerah Genangan Banjir DAS Sei Sikambing Dengan Sistem Informasi Geografis', 9(2), pp. 165-178. doi: http://dx.doi.org/10.29103/tj.v9i2.233. 